\title{
Memento mori
}

\section{Christina Aus der Au}

Prof. Dr. theol., Mitglied der Redaktion Ethik

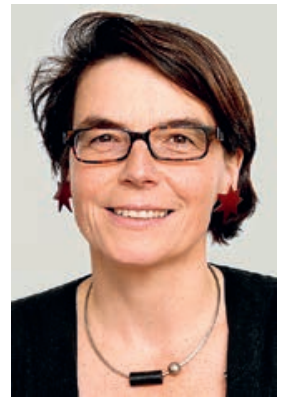

Unfassbar. Ein guter Kollege ist gestorben. Einfach so, plötzlich. Mitten aus dem vollen Leben heraus. Der Alltag bricht zusammen.

Nicht zum ersten Mal ist jemand, den ich zum engeren Bekannten- oder gar Freundeskreis zähle, aus heiterem Himmel einfach nicht mehr da. Plötzlich eine Todesnachricht: Herzinfarkt, Verkehrsunfall, spät diagnostizierter aggressiver Krebs oder ein Aneurysma. Gesund und tot, wie man sagt.

Für die Familie ist es furchtbar. Von einem Tag auf den anderen ist nichts mehr, wie es war. Wird nie mehr sein, wie es war. Und es ist für die Angehörigen wohl nur ein kleiner Trost, dass dies eine Art ist, aus dem Leben zu scheiden, wie es sich viele erhoffen. Möglichst im Schlaf, oder wenigstens schnell. Am liebsten eben gesund und tot, ohne viel davon zu merken. Ganz im Sinne Woody Allens, der gesagt haben soll: «Ich möchte nicht sagen, dass ich mich vor dem Tod fürchte. Ich möchte nur nicht da sein, wenn er zu mir kommt.»

Das Leben leben, auch gerne alt werden, aber lieber nicht alt sein, nicht mit all den Beschwernissen des Alters, nicht leiden müssen, nicht die Familie belasten mit einer schweren Krankheitszeit, mit hohen Kosten, nicht merken, wie langsam der Körper altert, die Lebenskraft schwindet oder, für viele noch beängstigender, das Gedächtnis schwindet, die Sprache, vielleicht sogar das Denken. Das ist eine so schreckliche Vorstellung für uns, die wir das Leben lieben und seine Möglichkeiten, dass wir einem plötzlichen Tod in der Blüte des Lebens zumindest theoretisch durchaus etwas abgewinnen können.

Schon die alten Griechen wussten es: Jung stirbt, wen die Götter lieben. Denen ersparen sie die Lasten des Alters, des Verfalls, des Dahinsiechens. Die bleiben gesund und lebenslustig in Erinnerung. Und es sind wir, die Zurückgebliebenen, denen nichts anderes übrig bleibt, als ohne sie weiterzuleben. «Bedenkt: den eignen Tod, den stirbt man nur, doch mit dem Tod der andern muss man leben", so schreibt es Mascha Kaléko. Und sie muss es wissen, sie verlor erst ihren einzigen Sohn, kurz darauf starb ihr Mann.

Wir, die Zurückgebliebenen, die das letzte Gespräch, den letzten Abschied, den letzten Blick in der Erinnerung drehen und wenden, uns zwischen Hättichdoch und Hättichdochnicht quälen und versuchen, mit dem
Unfassbaren weiterzuleben. Mit dem kleinen Trost, dass es für den Verstorbenen ein schöner Tod, weil ein schneller Tod war, und ihm so wahrscheinlich viel Leiden erspart geblieben ist.

Was ich kürzlich gelesen habe, hat mich allerdings nochmals zum Nachdenken gebracht. Ein solches Denken sei modern, früher habe man gerade nicht um einen schnellen Tod gebetet, sondern um einen sanften Tod. «Wollst endlich sonder Grämen aus dieser Welt uns nehmen durch einen sanften Tod», so Matthias Claudius in seinem Abendlied «Der Mond ist aufgegangen». Er schrieb diese Zeilen in einer Zeit, in welcher der Tod, sei es im Krieg oder an Krankheit, in seiner schnellen wie in seiner langsamen Variante schrecklich präsent war. Ein Tod, der völlig unvorbereitet, ohne Reue und Busse und ohne den Zuspruch der Sündenvergebung aus dem Leben reisst, ist in diesem Denken das Gegenteil eines sanften Todes. Mit sich und seinen Mitmenschen versöhnt - und, versehen mit den Sterbesakramenten, auch mit Gott - kann man hingegen getrost und sanft aus dem Leben scheiden.

Letzteres ist in unserer säkularisierten Welt wahrscheinlich nicht mehr so präsent. Sich in Ersterem zu üben, in der Versöhnung mit seinen Nächsten - und vielleicht auch mit den Ferneren -, ist aber eine Dimension dessen, was unter dem Stichwort «Memento mori», gedenke des Todes, für den mittelalterlichen Mönch ebenso zum guten Leben gehörte. Auch für die alten Römer bildete das gute Sterben den Endpunkt eines guten Lebens. So schreibt der Philosoph Seneca in seinen Briefen an Lucilius: «Vor dem Eintritt in das Alter sorgte ich dafür, gut zu leben, im Alter, gut zu sterben; gut sterben aber heisst, gern sterben.»

So weit bin ich definitiv noch nicht. Auch mein Kollege war es nicht. Er hätte noch so viel vorgehabt. Seine Familie hätte ihn noch so gebraucht. Wir hätten ihn noch so gerne bei uns gehabt. Der Tod nimmt keine Rücksicht auf unsere Wünsche. Der schnelle Tod schon gar nicht.

Und so nehme ich mir vor, mitten im guten Leben immer mal wieder den Tod ein kleines bisschen einzuüben: das Loslassen, das Versöhnen, das Vergeben. Es macht den endgültigen Tod nicht viel leichter, den eigenen nicht und schon gar nicht den der anderen. Aber vielleicht ein bisschen sanfter, wenn er denn doch plötzlich kommen sollte. 